\title{
A general fixed point method for the stability of the monomial functional equation
}

\section{LIVIU CĂDARIU and VIOREL RADU}

\section{ABSTRACT.}

In this paper, we extend the ideas in [Cădariu, L. and Radu, V., A general fixed point method for the stability of Jensen functional equation, Bull. Şt. Univ. Politehnica Timişoara, Ser. Mat.-Fiz. 51(65) (2006), No. 2, 63-72] to obtain some general stability results for monomial functional equations in $\beta$-normed spaces. The fixed point alternative together the error estimations for generalized contractions of type Bianchini-Grandolfi are pointed out, and then used as fundamental tool. Some applications and examples which emphasize the very general hypotheses, are also given.

DEPARTMENT OF MATHEMATiCS

"POLITEHNicA" University OF TimişOARA

PiAŢA Victoriei 2, 300006 TimişOARA, ROMANia

E-mail address: liviu.cadariu@mat.upt.ro, lcadariu@yahoo.com

DEPARTMENT OF MATHEMATICS

WEST UNIVERSITY OF TIMIŞOARA

FACULTY OF MATHEMATICS AND COMPUTER SCIENCE,

VASILE PÂRVAN 4, 300223 TIMIŞOARA, ROMANIA

Received: 31.10.2010; In revised form: 30.06.2011; Accepted: 30.11.2011

2010 Mathematics Subject Classification. 39B62, 39B72, 39B82, 47H09.

Key words and phrases. Monomial functional equation, fixed points, stability. 